\title{
Tissue Expansion in Children
}

\author{
Tara L. Braun, BS ${ }^{1} \quad$ Kristy L. Hamilton, MD ${ }^{1} \quad$ Laura A. Monson, MD ${ }^{1} \quad$ Edward P. Buchanan, MD ${ }^{1}$ \\ Larry H. Hollier, Jr., MD, FACS ${ }^{1}$ \\ ${ }^{1}$ Division of Plastic Surgery, Baylor College of Medicine, \\ Houston, Texas \\ Address for correspondence Larry H. Hollier, Jr., MD, FACS, Division of \\ Plastic Surgery, Baylor College of Medicine, 6701 Fannin St., Suite \\ Semin Plast Surg 2016;30:155-161. \\ 610.00, Houston, TX 77030 (e-mail: larryh@bcm.edu).
}

\author{
Abstract \\ Keywords \\ - tissue expansion \\ - pediatric \\ reconstructive \\ surgery \\ - complication \\ prevention and \\ management
}

Tissue expansion is a well-established surgical method that has been creatively applied to the management of many congenital and acquired pediatric conditions, including the removal of giant congenital melanocytic nevi and the separation of conjoined twins. Careful preoperative planning and patient follow-up are required to achieve the proper results and minimize complications. Special considerations for pediatric patients are present during each step of the process, from patient selection to postoperative care. The complication rate in tissue expansion remains high, though measures can be taken to reduce and effectively manage these complications.
Over the last 30 years, tissue expansion has developed into a powerful surgical modality to grow skin and soft tissue where it is lacking. Whereas other surgical techniques attempt to replace tissue with something similar, tissue expansion has the unique capability of providing more of the same adjacent tissue of a specific quantity and quality that is desirable for local reconstruction. The expanded tissue provides a good match to the recipient site in terms of color, texture, hairbearing capability, and sensation. ${ }^{1,2}$

The principle of tissue expansion was first employed by Neumann in 1957 when he placed an inflatable rubber balloon subcutaneously to expand temporal skin while reconstructing an ear. ${ }^{3}$ The concept remained largely unused until Radovan revisited it in 1976 when he expanded an arm flap to acquire additional tissue to close an adjacent defect. ${ }^{4}$ Radovan then applied tissue expansion to breast reconstruction after a mastectomy. ${ }^{5,6}$ Austad and Rose introduced the self-inflating tissue expander, which functions by allowing osmosis to expand semipermeable implants containing a highly concentrated saline solution. ${ }^{7,8}$ Ultimately, the Radovan model of surgeon-controlled inflation gained more traction as the expansion was more reliable and had lower rates of tissue necrosis. ${ }^{9}$

\section{Tissue Effects}

When tissue is expanded, various histological changes can be noted across tissue types. The epidermis thickens via hyper- keratosis acanthosis and increased mitotic activity, which is a fleeting phenomenon that resolves after 6 months. The dermis thins by 30 to $50 \%$, which can be the limiting factor in tissue expansion because overexpansion can risk skin breakdown and implant extrusion. The dermal thinning resolves after 2 years. Additional changes in the dermis include an increase in collagen deposition, realignment of elastic fibers in a parallel fashion, thickening and clustering of elastic fibers, and spreading of hair follicles and sweat glands. Skeletal muscle atrophies, but maintains its function despite irregularly oriented myofibrils and myofilaments. Adipose tissue remains permanently diminished by as much as $50 \%{ }^{10}$ The technique has been compared with the delay phenomenon in that it vastly increases the vascularity of the tissue surrounding the implant capsule, which is a dense network of collagen fibers produced by fibroblasts. This capsule appears within days of surgery and becomes thickest at 2 to 2.5 months following expansion. ${ }^{10,11}$ Expanded flaps, as a correlative, have an increased survival of $117 \%$ compared with nonexpanded flaps. ${ }^{12}$ The associated rapid angiogenesis is driven by high levels of vascular endothelial growth factor in expanded tissue, resulting in the proliferation of blood vessels between the capsule and surrounding native tissue. ${ }^{11}$

The creep principle governs the expansion process. Mechanical creep is the term given to describe the physical forces that alter the biomechanics of the skin when it is acutely stretched. ${ }^{11,13}$ This change can be witnessed intraoperatively
Issue Theme Pediatric Plastic Surgical Procedures; Guest Editors, William C. Pederson, MD, and Larry H. Hollier, Jr., MD, FACS
Copyright $\odot 2016$ by Thieme Medical Publishers, Inc., 333 Seventh Avenue, New York, NY 10001, USA. Tel: +1(212) 584-4662.
DOI http://dx.doi.org/ 10.1055/s-0036-1593479. ISSN 1535-2188. 
and occurs secondary to several factors including dehydration of the expanded tissue that has been wrung of its fluid, realignment of the collagen fibers in a parallel position, microfragmentation of elastic fibers, and the mechanical movement of adjacent tissue from outside the zone of expansion toward the implant site. ${ }^{10}$ Biological creep pertains to growth secondary to the cellular reaction to the expansion process. When tensile forces are applied to the cells, a signal cascade is induced that leads to the production of collagen fibers and proliferation of vessels, fibroblasts, and epidermal cells. The force required to maintain tissue expansion decreases over time, which is referred to as stress relaxation. $^{2}$

\section{Tissue Expansion in Pediatric Patients}

Tissue expansion is an excellent tool to reconstruct defects when other donor sites are unavailable or unacceptably morbid to the patient, and can be used to close larger wounds. The expansion process is cost effective, repeatable, and avoids the functional or cosmetic downside of having a donor site. The downside of tissue expansion is that it requires multiple stages and multiple outpatient visits, which prolongs the reconstruction process. Additionally, the process causes a dramatic, albeit transient, deformity that can be distressing to the patient. ${ }^{9}$ Tissue expansion is also rife with complications, with infection being the most common complication in children. ${ }^{14}$
Pediatric patients, given their size, have a baseline paucity of tissue to reconstruct defects. As such, pretransfer expansion of suitable donor sites to increase the amount of tissue used in reconstruction can be a helpful tool for the pediatric plastic surgeon. The principle may be applied to full-thickness skin grafts, pedicled and free flaps, and flaps with both cutaneous and fascial components. ${ }^{9}$

Tissue expansion has many indications in the pediatric population. Giant congenital melanocytic nevi can be removed via single-staged or serial expansion and excision. ${ }^{15}$ In conjoined twin separation, tissue expanders have been used to produce extra tissue to cover deficits present upon separation (-Fig. 1). Additional applications of pediatric tissue expansion include but are not limited to microtia, amastia, burn scars, aplasia cutis congenita, meningomyeloceles, hemangiomas, scrotal reconstruction, midfacial clefts, vaginal agenesis, Parry-Romberg syndrome, and Poland sequence. $^{15}$

Relative contraindications to tissue expansion include previous or anticipated radiation therapy and expansion near an open wound. Absolute contraindications include open infection, already tight tissue, and expansion near a malignancy or under a skin graft. ${ }^{2}$ Additionally, in the pediatric population, the surgeon must consider anticipated patient compliance and the reliability of the parents.
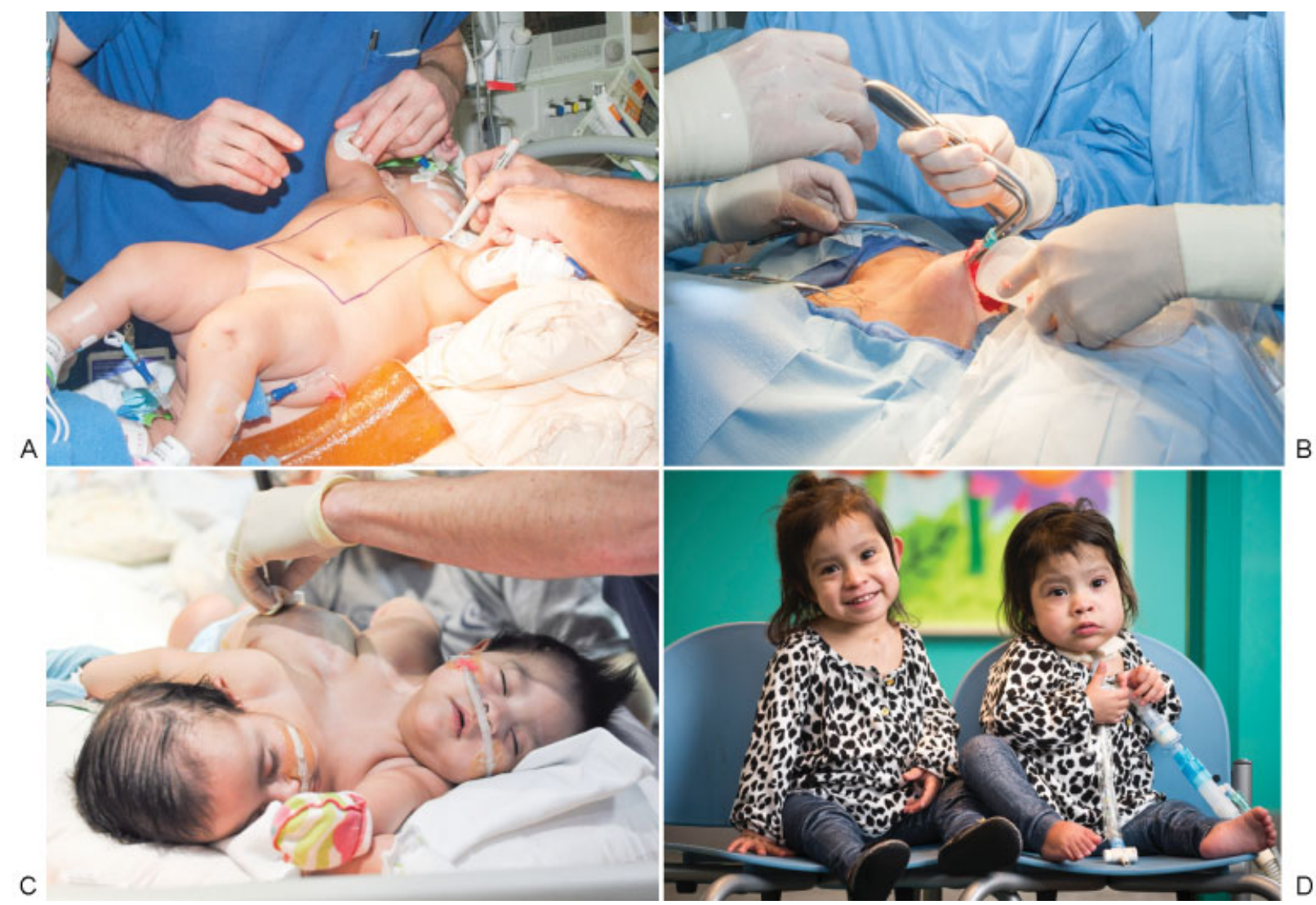

Fig. 1 Prior to the separation of conjoined twins, the abdominal skin was expanded for coverage of soft tissue deficits. (A) The location of the tissue expander pocket was planned preoperatively. (B) Insertion of a partially inflated expander into the dissected pocket. (C) Expander inflation was performed in the clinic until the expander reached its desired volume. (D) The twins after tissue expander removal and successful separation. 


\section{Preoperative Planning}

The incision, flap design, type of expander, expander placement, and expander movement in relation to the defect must all be considered preoperatively for successful tissue expansion. ${ }^{11}$ Preoperative education for the child and family is also very important and should include familiarization with the expander, how the inflation process works, any associated discomfort, and possible complications of the tissue-expansion process. ${ }^{16}$

\section{Expander Selection}

There are many expander designs that vary in style, shape, size, contour, and material. Whereas most expanders are internally placed under the soft tissue to be expanded, tissue expanders can also be externally applied. Internal expanders are placed in the dissected pocket beneath the to-be-expanded region, and an injection port can be accessed to serially inflate the expander to the desired volume as time progresses. These devices are typically made of a flexible silicone elastomer that allows the reservoir to expand via saline injection.

The injection port may be directly integrated into the device or located adjacent to the implant, connected by tubing. ${ }^{2}$ The benefit of the integrated port lies in its avoidance of an additional implantation site. However, it does carry the risk of implant puncture during inflation if the child moves, resulting in subsequent device failure. Alternatively, remote injection ports can be used, with mini- or low-profile ports available that place less pressure on overlying skin. Miniports are especially useful in infants. ${ }^{16}$ Remote ports can be internally or externally located. External ports avoid additional pain from injections, which is helpful when parents will be filling the device from home. External ports also have the benefit of reduced dissection and earlier detection of leaks. Although implants with external ports show high rates of bacterial colonization due to their confluence with the outside world, their increased risk of complications compared with internal ports has been disputed. ${ }^{15,17-19}$ Internal ports have the downside of requiring injection through the skin, but this experience can be made less unpleasant for the child with the use of an anesthetizing cutaneous cream. ${ }^{18}$

Expanders may have rigid or soft bases, resulting in unidirectional versus multidirectional expansion, respectively. Often, the tissue expander must be placed against solid tissue such as bone or cartilage to ensure that expansion occurs in the desired direction. Expanders with semirigid backing should be used on the abdomen, where inwardly directed pressure may give the child a sense of intra-abdominal fullness. ${ }^{15}$ Rigid backing should also be used when there is concern about distortion of underlying structures. ${ }^{20}$

The implant surface may be smooth versus textured and the shape of the expander depends on desired location and surgeon preference. Rectangular expanders are typically used for the abdomen and extremities, while crescent expanders are used for the scalp. ${ }^{2,20,21}$ Custom implants may also be designed that allow for any size and shape to be created, such as kidney-shaped expanders for congenital microtia reconstruction or custom-sized implants to fit a specific patient (- Fig. 2). ${ }^{22}$ Additionally, the surgeon may opt for several

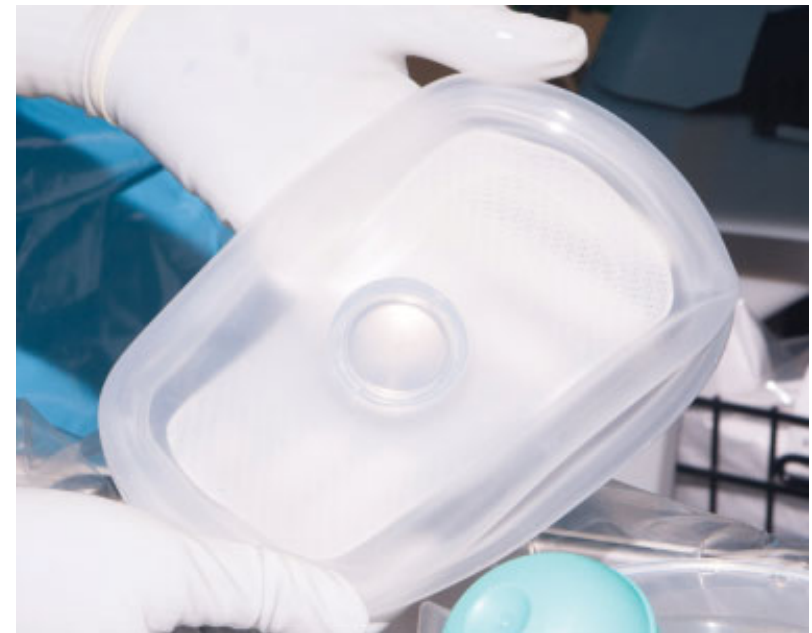

Fig. 2 A rectangular-shaped tissue expander with an integrated port was custom designed for the expansion of abdominal tissue.

expanders versus the use of one larger expander depending upon the tissue required for reconstruction. Whereas multiple small expanders may allow for less distortion and more rapid expansion, the use of multiple expanders has a higher complication rate. ${ }^{17,23,24}$

In serial tissue expansion, the same or a larger expander is used to expand the same skin flaps after partial correction of a large defect. A delay of several months is required after the first reconstruction to allow wounds to heal completely and avoid migration of the implant in the next expansion. ${ }^{15}$ The scalp of children thins excessively after two expansions, whereas adults can tolerate three to four scalp expansions sequentially. In the abdomen, children can tolerate two or three serial expansions, but abdominal expansion with a large prosthesis is accompanied by significant discomfort and deformity for the patient. ${ }^{17}$ Higher complication rates also occur with serial expansion of the same tissue. ${ }^{25}$

Finally, tissue expanders may be self-inflating versus traditionally expanded with the injection of sterile saline into the device's port. The self-inflating devices function by allowing osmosis to expand semipermeable implants containing an active hydrogel, as compared with highly concentrated saline solution of the original model. The benefit of this kind of device is that it requires fewer visits and less pain, as the device is not accessed externally, which also reduces the risk of infection. ${ }^{26}$ These devices have shown utility in scrotal expansion, given limited mobility and space in the area that make valve positioning difficult. ${ }^{27}$ The surgeon is currently unable to control the rate and direction of this method of expansion, though a new direction-controlled self-inflating device has been developed and tested in animal models. ${ }^{28}$

To allow adequate expansion, the base diameter of the chosen expander should be 2 to 2.5 times the diameter of the defect. Tissue available for a simple advancement flap equals the circumference of the expanded skin (dome length) minus the base diameter of the expander. ${ }^{2}$ Contraction of expanded tissue is expected, so the flap should be 30 to $50 \%$ longer than necessary when the expander is maximally filled. ${ }^{15}$ 


\section{Incision and Pocket}

The incision for the tissue expander must be planned preoperatively and take into consideration the effects of expansion on the overlying skin, potential donor-site morbidity, and the planned reconstruction. ${ }^{15}$ Always consider the blood supply to the flap and where the port will be placed. When possible, the incision should be aligned perpendicular to the long axis of the expander to minimize tension on the incision. ${ }^{4}$ Depending on the indication, the incision can be placed within the existing scar, at the lesion's border, or in an area that will be resected ( - Fig. 3 ).

The expander pocket should be $2 \mathrm{~cm}$ or greater from the incision to minimize the risk of dehiscence or expander exposure. $^{16,18}$ Make the pocket 1 to $2 \mathrm{~cm}$ larger than the expander on each side so the implant will not have any folds. ${ }^{18}$ The level of dissection depends on the expander location and the type of flap planned. The pocket is usually placed on top of the deep fascia unless the muscle is to be expanded as well. ${ }^{15}$ The placement of the expander is generally subgaleal in the scalp, suprafascial in the trunk and limbs, and submuscular in the breasts. ${ }^{2,9}$

\section{Expansion Process}

\section{Insertion}

Expander insertion is performed in the operating room with the patient under general anesthesia. Antibiotics are given preoperatively along with several other measures to prevent infection. The incision is made as planned and the pocket dissected bluntly to preserve overlying vessels. Meticulous hemostasis and aseptic technique are necessary at this stage. ${ }^{29}$ The surgical team should change their gloves prior to contact with the expander. The expander is bathed in an antibiotic solution and the dissected pocket irrigated with povidone-iodine before expander insertion. ${ }^{9}$ The expander is filled to 10 to $20 \%$ capacity at the time of placement, which helps prevent hematoma and seroma formation and smooths out the implant to minimize fold extrusion. ${ }^{17}$ Drains are used on a case-by-case basis depending on the expander location and surgeon preference, and some authors suggest continuing antibiotics until drain removal 5 to 10 days later. ${ }^{18,30}$ The incision is closed in layers with absorbable suture.

Drains prevent fluid accumulation in the tissue, but serve as a nidus for possible infection. One retrospective study showed that the use of drains does not affect the rate of hematomas, seromas, and infections in pediatric tissue expansion. ${ }^{23}$ However, no prospective studies have been done on the use of drains or pre- and postoperative antibiotics in pediatric tissue expansion, so clinical practice varies widely.

\section{Inflation}

Inflation begins 1 to 3 weeks following expander placement, allowing sufficient time for the incision to heal. ${ }^{9,25}$ For children, the inflation process may be especially frightening at first, which is why preoperative education is very important to familiarize the child and parents with the process. ${ }^{16}$ Fillings typically occur every 3 to 7 days and then continue until desired expansion is attained over 6 to 12 weeks. In pediatrics, smaller, more-frequent fillings result in less pain

A
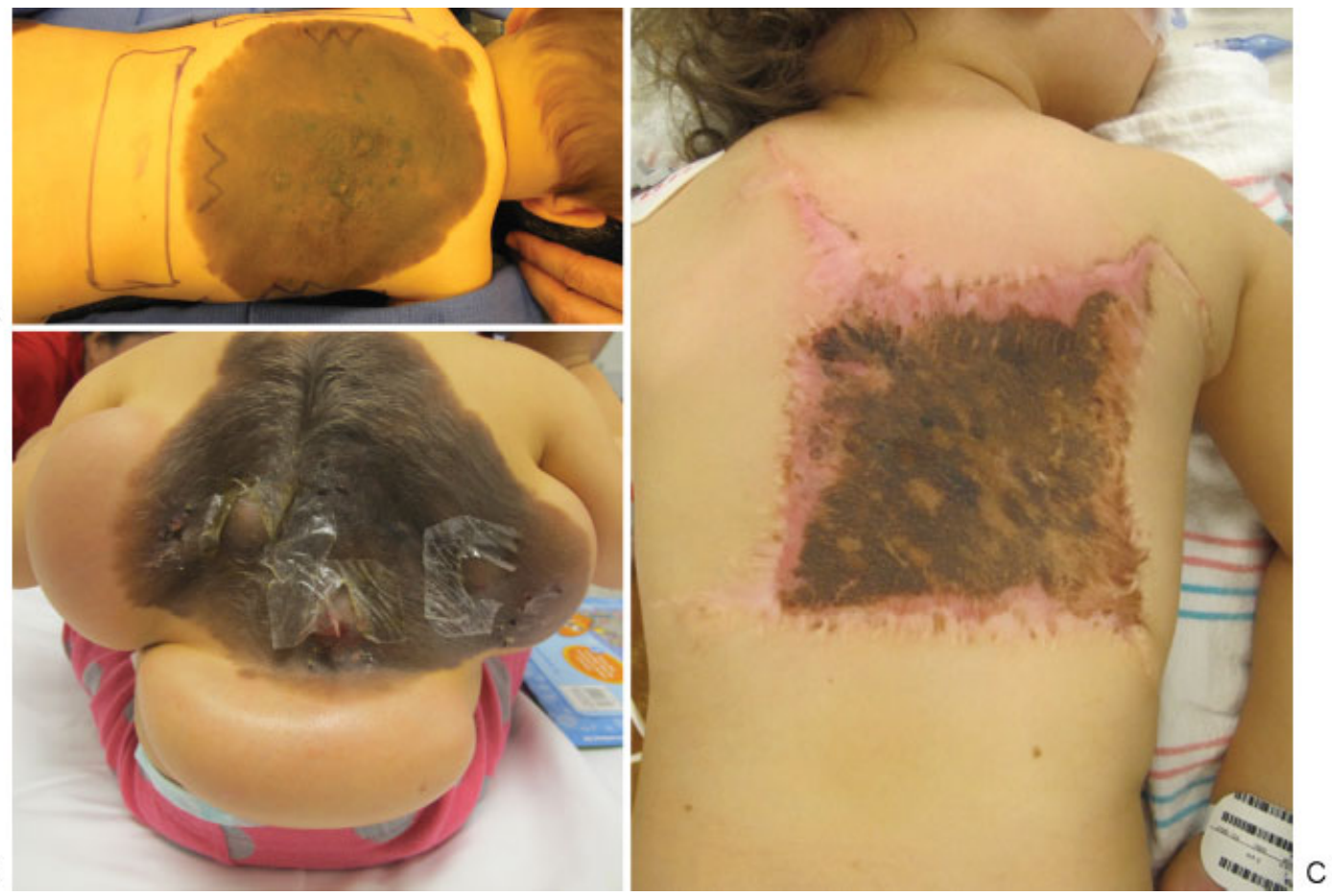

B

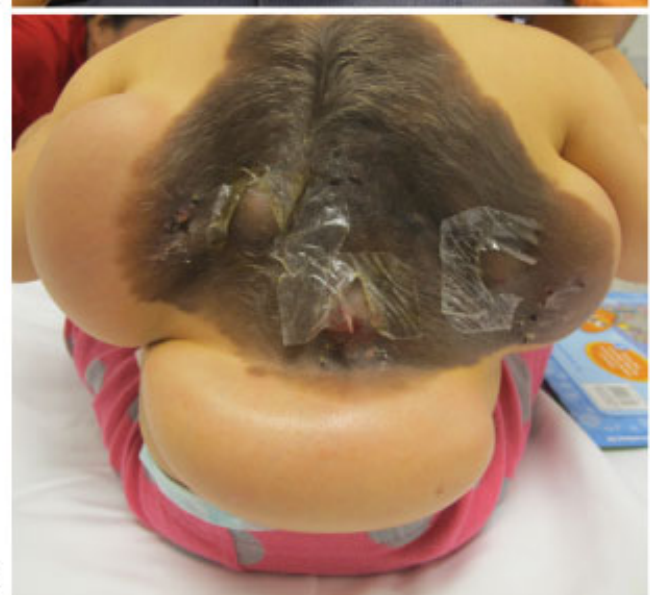

Fig. 3 Tissue expansion was used for the removal of a giant congenital nevus. (A) Incisions were planned preoperatively and placed within the lesion. (B) The inflation process slowly expanded the tissue surrounding the nevus. (C) The expanded tissue flaps were advanced, allowing excision of a large portion of the nevus. 
and thus are better tolerated, especially in patients with external ports. Expansion of the forehead and scalp can be particularly uncomfortable at first requiring small volumes, but the skin loosens after several weeks allowing larger injections. $^{17}$

Inflation is performed using sterile technique and can be done during an office visit. Home expansion is safe when parents are fully educated on the proper method. This counseling includes teaching sessions that allow the parent or family member to practice on an expander, and complete written instructions provided for them to take home. Several home expansions should be followed by an office visit that allows the clinician to re-evaluate the child. The family is instructed to call the office if any problems or complications arise. $^{11,16}$

Prior to inflation, prep the skin carefully with povidoneiodine and wear sterile gloves (-Fig. 4). During needle insertion, the child should be gently restrained either lying down or held in someone's lap. ${ }^{17}$ Fill the expander until the patient senses discomfort or the overlying skin blanches. The skin should be tense, but there should be no extreme pain. ${ }^{2}$ Expanders can be safely filled to volumes several times the manufacturer's stated capacity. ${ }^{15}$

\section{Removal and Reconstruction}

During expander removal, the original incision is used to access the expander. The capsule can be scored perpendicular to the direction of advancement to facilitate maximum advancement of expanded tissue. ${ }^{2,9}$ Alternatively, the capsule can either be left intact or fully excised. ${ }^{11,17}$ The capsule has a resilient surface. Thus, in the extremities, it can be transposed over joints and tendons to decrease adhesions. ${ }^{17}$

Many reconstructive options are available with expanded tissue and are individualized to the particular patient, taking into consideration the size and location of the defect. Expanded tissue is often used as an advancement flap, though rotation flaps and transposition flaps may also be designed for neighboring defects. For example, advancement or rotation flaps achieve the best results in scalp expansion, whereas

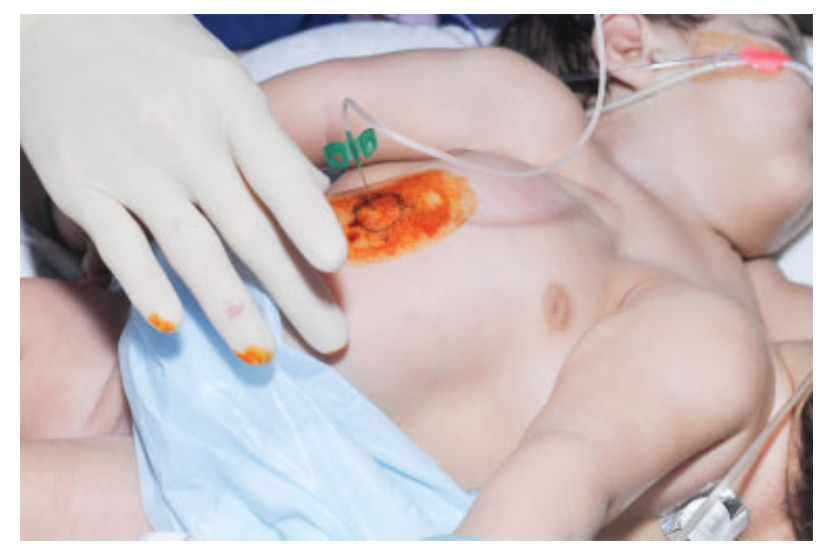

Fig. 4 Tissue expander inflation is performed in a clinic or at home using sterile technique. The skin is prepped with povidone-iodine. Then, a 23-gauge butterfly needle connected to tubing is placed within the port to allow fluid insertion. transposition flaps may provide better coverage for larger defects over the shoulder and arm. ${ }^{17,31}$ Transposition flaps allow better "reach" of the flap to cover larger defects, have shown less scar contracture, and can provide better contour. The downside is that transposition flaps have greater scar burden than simple advancement flaps. ${ }^{20,31}$ For reconstruction of the lateral face, the neck can be expanded and a Mustardé cheek rotation flap used to cover the defect. ${ }^{17}$ Expanded distant tissue may also be used as a pedicled flap, such as an expanded pedicled flap from the abdomen transferred to the forearm. ${ }^{20}$ Additionally, free-expanded deltopectoral flaps have been used for repair of facial burn scars, and expanded full-thickness skin grafts from the neck are used to reconstruct the forehead. ${ }^{17,32}$ Expanded fullthickness skin grafts tend to be extremely resilient and grow well with children over time. ${ }^{17}$

\section{Complications of Tissue Expansion}

\section{Risk Factors}

Complication rates of as high as $40 \%$ have been reported in infants and children, although recent series report rates of 13 to $20 \%{ }^{15,18,23,29,30}$ Studies report conflicting evidence on age, indication for expansion, and location of expansion as risk factors for complications. ${ }^{15,18,23,29,33}$ Children under age 12 tend to be less compliant, are more likely to traumatize their expander site, and have less tissue available to expand. ${ }^{18,23}$ Their skin and soft tissue are also thinner than that of an adult and thus more susceptible to trauma. ${ }^{17}$ However, their skin is also more elastic, better vascularized, and expands more easily, which may help explain why a recent study showed no difference in complication rates between adult and pediatric populations who underwent tissue expansion. ${ }^{18}$ In terms of location, many studies agree that the lower limb has the highest complication rate. This has been explained by limitations of vascularity and available tissue in the area, along with the lower extremity being in frequent motion. ${ }^{15,18,19,23}$ The head and neck also show high rates of complications due to the presence of bony contours and the tendency of expanders to slip downwards. ${ }^{9,15,24,29,33}$ The neck also has thin subcutaneous tissue that is subject to constant shearing forces during movement. ${ }^{33}$ In the head and neck region, use smaller volume expanders and avoid their placement directly over bony prominences. ${ }^{29}$

\section{Management and Prevention}

Minor complications that do not delay reconstruction include pain, scar widening, temporary disfigurement, seroma, dog ears, and transient neuropraxia. ${ }^{11,15,17}$ Dog ears usually settle during the expansion process and do not need to be trimmed. Scar widening can occur as children grow and might become a cosmetic problem, so scar revision can be performed when the patient is 16 to 18 years old. ${ }^{17}$

Major complications that can delay reconstruction include infection, implant exposure with or without extrusion, hematoma, failure of device, and skin necrosis or flap ischemia. ${ }^{11}$ Infection is the most common complication, with rates as high as 4.4 to $9.3 \%$ of the total number of expanders in 
pediatric patients. ${ }^{14}$ Infection can occur during insertion, inflation, or may come from an adjacent wound or hematogenous seeding. Due to the high rates of infection, clinicians should have a low threshold to place children on antibiotics for low-grade fevers, early signs of erythema on the flap or incision, upper respiratory infections, or documented bacterial infections in family members. ${ }^{14}$ If there is obvious infection of the pocket early in the course of expansion, the expander should be removed, the wound irrigated, and expansion reattempted in 3 or 4 months. If the infection occurs later in the expansion process, the expander is removed and reconstruction performed with the partially expanded tissue, followed by repeat expansion if necessary. ${ }^{17}$ An infection of the port can be treated with an initial trial of antibiotics. $^{29}$

If the expander becomes exposed soon after placement, it should be removed. Minimal or late exposure can potentially be treated with dressing changes and local antiseptic ointment, permitting continued expansion. ${ }^{9,11}$ Alternatively, the surgeon can remove the exposed expander, advance the partially expanded flap, and then reinsert another expander once the flaps have healed. ${ }^{15}$ Expander rupture or deflation due to needle puncture are both treated with expander replacement, and hematomas are treated with evacuation and irrigation of the cavity. ${ }^{9,15}$

Skull deformities during the expansion process have been reported. Increased bone apposition at the periphery of the expander, suture widening, and bone reaction under the expander have been evidenced on computed tomography and observed clinically. ${ }^{34}$ However, changes in cranial bones and sutures normalize 3 to 9 months after expander removal. ${ }^{15,33-36}$ One author noted that if the deformity was prominent during expander removal, the surgical team contoured the skull with a high-speed bur to create a smooth transition. ${ }^{36}$ The correct age to perform scalp expansion is controversial. Expansion in patients under 9 months can affect the fontanelles and cranial sutures, so some authors suggest waiting until the patient is 12 to 18 months old when the skull is solid enough to prevent significant erosion. ${ }^{17,36}$

The best way to prevent complications is via proper patient selection and education. The patient and family need to be highly motivated, able to cooperate with treatment, and informed of the physical changes and possible complications that accompany expansion. ${ }^{9}$

Financial Disclosures/Commercial Associations Dr. Hollier is a consultant for Stryker Corporation.

\section{References}

1 Zöllner AM, Buganza Tepole A, Gosain AK, Kuhl E. Growing skin: tissue expansion in pediatric forehead reconstruction. Biomech Model Mechanobiol 2012;11(6):855-867

2 Janis JE. Essentials of Plastic Surgery. 2nd ed. Boca Raton, FL: CRC Press; 2014:50-65
3 Neumann C. The expansion of an area of skin by progressive distension of a subcutaneous balloon. Plast Reconstr Surg 1957; 19:124-130

4 Radovan C. Tissue expansion in soft-tissue reconstruction. Plast Reconstr Surg 1984;74(4):482-492

5 Radovan $\mathrm{C}$. Reconstruction of the breast after radical mastectomy using a tissue expander. ASPRS Plast Surg Forum 1978;1:41

6 Radovan C. Breast reconstruction after mastectomy using the temporary expander. Plast Reconstr Surg 1982;69(2):195-208

7 Austad ED. Complications in tissue expansion. Clin Plast Surg 1987;14(3):549-550

8 Austad ED, Rose GL. A self-inflating tissue expander. Plast Reconstr Surg 1982;70(5):588-594

9 Malata CM, Williams NW, Sharpe DT. Tissue expansion: an overview. J Wound Care 1995;4(1):37-44

10 Johnson TM, Lowe L, Brown MD, Sullivan MJ, Nelson BR. Histology and physiology of tissue expansion. J Dermatol Surg Oncol 1993; 19(12):1074-1078

11 Thorne C, Kevin CC, Gosain A, Geoffrey CG, Mehrara BJ. Grabb and Smith's Plastic Surgery. 7th ed. Philadelphia, PA: Wolters Kluwer Health/Lippincott Williams \& Wilkins; 2007

12 Manders EK, Schenden MJ, Furrey JA, Hetzler PT, Davis TS, Graham WP III. Soft-tissue expansion: concepts and complications. Plast Reconstr Surg 1984;74(4):493-507

13 Santiago GF, Bograd B, Basile PL, Howard RT, Fleming M, Valerio IL. Soft tissue injury management with a continuous external tissue expander. Ann Plast Surg 2012;69(4):418-421

14 Adler N, Dorafshar AH, Bauer BS, Hoadley S, Tournell M. Tissue expander infections in pediatric patients: management and outcomes. Plast Reconstr Surg 2009;124(2):484-489

15 Rivera R, LoGiudice J, Gosain AK. Tissue expansion in pediatric patients. Clin Plast Surg 2005;32(1):35-44, viii

16 Bauer BS, Vicari FA, Richard ME. The role of tissue expansion in pediatric plastic surgery. Clin Plast Surg 1990;17(1):101-112

17 Mathes SJ. Plastic Surgery. 2nd ed. Philadelphia, PA: Saunders; 2006

18 Adler N, Elia J, Billig A, Margulis A. Complications of nonbreast tissue expansion: 9 years experience with 44 adult patients and 119 pediatric patients. J Pediatr Surg 2015;50(9):1513-1516

19 Huang X, Qu X, Li Q. Risk factors for complications of tissue expansion: a 20-year systematic review and meta-analysis. Plast Reconstr Surg 2011;128(3):787-797

20 Margulis A, Bauer BS, Fine NA. Large and giant congenital pigmented nevi of the upper extremity: an algorithm to surgical management. Ann Plast Surg 2004;52(2):158-167

21 Jackson OA, Low DW, Larossa D. Conjoined twin separation: lessons learned. Plast Reconstr Surg 2012;129(4):956-963

22 Kludt NA, Vu H. Auricular reconstruction with prolonged tissue expansion and porous polyethylene implants. Ann Plast Surg 2014;72(Suppl 1):S14-S17

23 Friedman RM, Ingram AE Jr, Rohrich RJ, et al. Risk factors for complications in pediatric tissue expansion. Plast Reconstr Surg 1996;98(7):1242-1246

24 Neale HW, High RM, Billmire DA, Carey JP, Smith D, Warden G. Complications of controlled tissue expansion in the pediatric burn patient. Plast Reconstr Surg 1988;82(5):840-848

25 Hudson DA, Lazarus D, Silfen R. The use of serial tissue expansion in pediatric plastic surgery. Ann Plast Surg 2000;45(6):589-593, discussion 593-594

26 Gronovich Y, Tuchman I, Binenboym R, Eizenman N, Golan J. Reconstruction with an osmotic tissue expander in pediatric patients. Plast Reconstr Surg 2012;129(5):863e-865e

27 Van Eeckhout GP, Vanmierlo B, Sen MK, Wylock P, Braeckman J. A new technique of expanding the underdeveloped scrotum. Plast Reconstr Surg 2010;126(2):101e-102e

28 Swan MC, Bucknall DG, Czernuszka JT, Pigott DW, Goodacre TEE. Development of a novel anisotropic self-inflating tissue expander: in vivo submucoperiosteal performance in the porcine hard palate. Plast Reconstr Surg 2012;129(1):79-88 
29 Elias DL, Baird WL, Zubowicz VN. Applications and complications of tissue expansion in pediatric patients. J Pediatr Surg 1991;26(1):15-21

30 Gibstein LA, Abramson DL, Bartlett RA, Orgill DP, Upton J, Mulliken JB. Tissue expansion in children: a retrospective study of complications. Ann Plast Surg 1997;38(4):358-364

31 Bauer BS, Margulis A. The expanded transposition flap: shifting paradigms based on experience gained from two decades of pediatric tissue expansion. Plast Reconstr Surg 2004;114(1):98-106

32 Song B, Zhao J, Guo S, et al. Repair of facial scars by the free expanded deltopectoral flap. Plast Reconstr Surg 2013;131(2): $200 \mathrm{e}-208 \mathrm{e}$
33 Hurvitz KA, Rosen H, Meara JG. Pediatric cervicofacial tissue expansion. Int J Pediatr Otorhinolaryngol 2005;69(11):1509-1513

34 El-Saadi MM, Nasr MA. The effect of tissue expansion on skull bones in the paediatric age group from 2 to 7 years. J Plast Reconstr Aesthet Surg 2008;61(4):413-418

35 Schmelzeisen R, Schimming R, Schwipper V, Heydecke G. Influence of tissue expanders on the growing craniofacial skeleton. J Craniomaxillofac Surg 1999;27(3):153-159

36 Gosain AK, Zochowski CG, Cortes W. Refinements of tissue expansion for pediatric forehead reconstruction: a 13-year experience. Plast Reconstr Surg 2009;124(5):1559-1570 